\title{
Tentative Analysis on Implications of Traditional Culture and Art Education for Teaching Mode of Architecture
}

\author{
Pinghan Zha \\ Wuhu Institute of Technology \\ Wuhu, Anhui, China, 241000
}

\begin{abstract}
In this paper, the author found the reasons of "success" and "failure" of current teaching mode of architecture, made a brief summary of "generality" and " individuality" of architectural education and its sticking points, and proposed three points of ideas to improve current teaching mode of architecture and help all architectural students make success, in combination with the successful experience of traditional creativity education in nurturing talents.
\end{abstract}

Keywords-traditional creativity education; education of architecture; generality; individuality; overall planning In this paper, the author found the reasons of "success" and "failure" of current teaching mode of architecture, made a brief summary of "generality" and " individuality" of architectural education and its sticking points, and proposed three points of ideas to improve current teaching mode of architecture and help all architectural students make success, in combination with the successful experience of traditional creativity education in nurturing talents.

\section{INTRODUCTION}

In the "Dream of Red Mansions - The Forty-eighth Chapter", Ms. Xiangling took poetry master Lin Daiyu as her teacher, under who guidance Xiangling made reading and writing exercises of poems. Later she practiced and accomplished total three poems about the moon, and the first two times, she failed, but the third time, she got a success. The poetry is "moonlight is bright, even if you want to hide it, it is difficult. The moon looks so beautiful and graceful, but lonely and deserted in nature, I'm so lonely. In the moonlight illuminating the land, the sound of pounding clothes can be heard without end. When the moon appears half, cock is crowing for morning, the five watches of the night will end and the dawn comes. The traveler boating in the river, thinks of his home when he heard the piping in the autumn moon. I look at the moon by leaning against the handrail in the upstairs, and Chang'e the goddess in the moon seeing the vicissitudes of life, can't help asked herself, 'Why not make people reunite, never separated?' "[1] The sisters in the Poetry Society said, "This poem is good, also ingenious and interesting", which is different from the comprehension of Xiangling. Zeng Guofan had difficulty of reading in his childhood, but he eventually became a famous official in the late Qing Dynasty, and took the leading position in literature an calligraphy, inheriting Tongcheng School's Fang Bao and Yao Nai styles and independently created the Xiangxiang School. His ancient Chinese prose is profound and generous, magnificent and grand, promoting Tongcheng School and eliminating its disadvantages, and his regular script and running script are both taken as model, spreading in the world. Smart and hard, both of them successfully created a charming works of art after they gradually appreciated and absorbed the creative essence of traditional art. Their road to success is reminiscent of a lush and fruitful orange tree, from the first step of " Deep-rooted and hard to move, due to your single-minded will", the second step of "Green leaves is rendered by white flowers, lush looking is like some", finally to the third step "Layers of branches with sharp thorns, full of round fruits"[2]. Each growth stage has its own unique significance, needing scientific cultivation of hardworking teachers.

Traditional Creative Education has enlightenment for teaching mode of architecture that should not be underestimated. Careful study on precious experiences of the former in cultivating the creative talents, helps us to improve the existing teaching mode of architecture and helps students of architecture fully display their talents.

\section{THE "SUCCESS" AND "FAILURE" OF CURRENT EDUCATION IN ARCHITECTURE}

The architect Li Zhu who graduated from Tsinghua University, says, "a student in our class had been Number One Scholar in a whole city of Fujian, unhappily he is enrolled by the Department of Architecture, actually he did not choose the right major, and has poor endurance of psychological press . Finally he ends his study in Tsinghua University only with a junior college diploma. Now no one has his whereabouts. It is a pity. "Such an intelligent student has had outstanding study ability and got success but failed in his study in Tsinghua University only due to his inadaptation to the current teaching mode of architecture, which is thought-provoking.

Some graduates of architecture can adopt to the ability training mode of the major syllabus, they learned design and can be described as the "success" of prevailing architectural education; at the same time things go athwart, the teaching 
mode carried out in accordance with the very comprehensive syllabus still has a "flaw." Although each student have experienced at least 12 times of architectural design or issues planning, the student can obtain knack is rare when they graduate. A significant proportion of outstanding students in high school feel no ability enough to get a smooth "comprehension" of their professional design when they face the architectural study in the universities and even when they graduate. They cannot obtain itemized professional competence set by teaching goals of the major, and not deal with strong skill requirements of other technical work, and even are unbearable for all kinds of psychological barrier caused by real burden.

\section{THE "GENERALITY" AND "INDIVIDUALITY" OF}

\section{ARCHITECTURAL EDUCATION AND ITS STICKING POINTS}

Roman architect and engineer Vitruvius had pointed out in his famous "Ten Books on Architecture" that "a architect have to possess multidisciplinary knowledge and various skills ... a architect should be good at writing, familiar with drawing, proficient in geometry, fully aware of various histories, often give an ear to philosophy, comprehend music, know medicine less or more, make acquainted with discussion of legal experts, bear knowledge of astronomy or celestial theories". Vitruvius also compares "full knowledge" to" a man's body", and "all kinds of knowledge" is equivalent to "human body", they are a whole, closely linked together, this is so-called "comprehending by analogy" [3]

From this, we know the generality of education in Science and Engineering, Humanities and Arts is to pursue "truth", "good" and "beauty", besides this, the education in architecture more reflects an unique pursuit of " individuality", which is to achieve mastery through a comprehensive study of different subject knowledge that is seemingly fragmented and various levels of skill.

Most scientists have pointed out that: Everyone has creativity (talent) and morbidity. They put people into four categories: people with strong creativity and morbidity, who tend to become a genius; people with normal creativity and morbidity, who are mediocre and even bourgeois; people with serious morbidly but limited creativity, who will become mentally ill; people with slight morbidity but strong creativity, who will give full play to their talents, but can not become a genius. We hardly assert the No. One Scholar Mr. $\mathrm{Li}$ is born to serious morbidity and thus become the "unfinished project" of architecture class and even a mental patient. Like many domestic and foreign artists who are obsessed with artistic creations but become mad, there may be many new scholars of architecture are infinitely confused in the Eastern and Western art concept while indulge their uninhibited imagination and unruly creativity, as if the flying moth is forever attracted by the flame, they inadvertently break the regular teaching pattern, to form the intricate and bewildering phenomena of design education from day to day.

Shakespeare said: "The madman, the lover and the poet are full of massive imagination, and they can see much more ghosts seen than that in the vast hell. The lover is as maniac as the madman, and he can see the beauty of Helen from an
Egyptian face. The poet turns his eyes, full of fine and ingenious madness, setting eyes from the sky to the earth and from the hell to the heaven." Su Shi had entangled in heavy ideological conflicts and been full of "massive" artistic imagination, during his creation of "Painting of Dried Wood and Strange Rock" "Fig .1". At all times, there are many artists with "both genius and madness ".

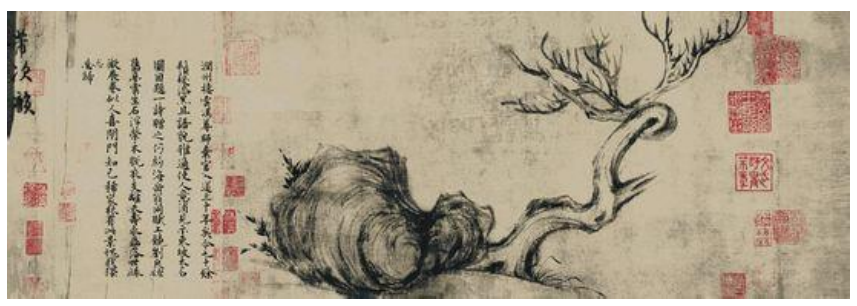

Fig. 1. The "Painting of Dried Wood and Strange Rock " by Su Shi in the Song Dynasty

Many well-known scholars in western psychology, sociology, art history and other academic fields get the scientific demonstration: the change of cognitive state must promote linkage between unique ideas and thinking. Original cognition is the source of the similarity between artist and mental patient. The outstanding artists in their creation, must imagine and create an artistic conception or story different from the reality, to accomplish their works with abnormal thinking. For a long term, they will have their thinking set and character set. The talented artists often suffer from severe mental hurt accordingly, and if their severe morbidity develops further, they will become mental patients, and even commit suicide for nervous breakdown. For example, Gauguin created his "magnificent works - "Where do We Come From? Who are We? Where are We Going?" "Fig. 2", with his greatest enthusiasm in 1898, and after that he suffered from mental difficulties. But if they have not completely lost contact with the reality, and when certain conditions are met, they will make earlier artistic creation for "the frequent close contact between creativity and affective disorder".

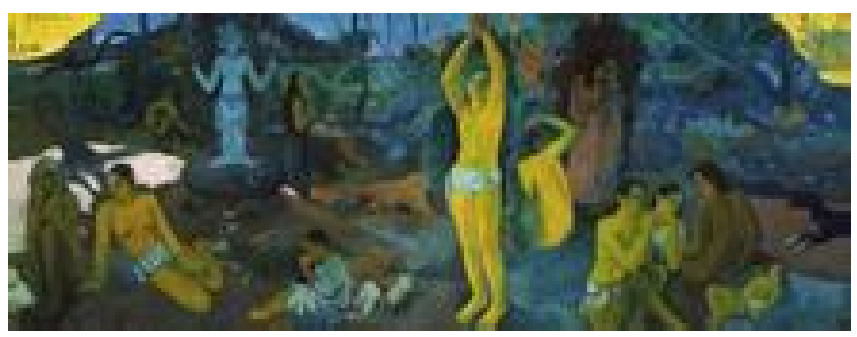

Fig. 2. Gauguin's "Where do We Come From? Who are We? Where are We Going? " in 1898

The trick proposed by the psychoanalyst Dr. Daniel • Nettle of Newcastle University for those people who are expected to develop their creativity is quoted: "If you have some strong suits, such as some unique ways to observe the world, while you do not lose your social skills, and then you can find a way to lead schizophrenic tendencies to the creativity, which will very attractive " [4]. The art theorist John Ruskin, the founder of modern design philosophy, 
believes that "the method of great art cannot be used for small art, and that of pure art not used in the design" [5]. By summing up their discussion, we find it is important to aptly adjust the rational relations between the fresh in architecture and the small art of design. Goethe has a dual personality, who did his job with skill and ease in the heavy and intricate Palace of Weimar and do well in his art creation. the students with the same type of Goethe can easily clarify the rational relations between the major of architectures and their past, nowadays and future, and in their talent or natural instincts, they make more or less deviation from the "stupid" students as required by the architect. At the same time, they should step out of the maze that cannot do without careful guidance of collective education.

\section{THREE POINTS OF ASSUMPTION TO IMPROVE THE EXISTING TEACHING MODE OF ARCHITECTURE}

"The Orange tree in the south will become poncirus when it is planted in the north of Huaihe River" is often used to describe the impact of educational environment for students. Unsuitable water and soil will change a orange tree into poncirus, which is reflected in the field architectural teaching. Please try the following three points of assumption and hope it is helpful for all students of architecture. We should make overall plan and consider all factors in the different period of consolidating foundation, developing fully and optimizing results, and finally become useful talents for the society.

\section{A. For A High Goal? or for A Middle Goal? to Construct A Mode of Introduction to "Consolidating Foundation" and Carrying out Different Teaching Framework for the Students in the Same Class.}

"If developing a high goal, a person may reach the middle level finally, and if developing a middle goal, he may reach the lower level finally. [6]", comes from Confucius's view of education. The "high goal", that is a mode of introduction to "consolidating foundation" and carrying out different teaching framework for the students in the same class, helps realize guidance by teacher and practice by individuality at the foundation teaching stage, to change the baseless and clueless state of architecture.

Successful traditional creativity education is often inseparable from the "hand feeling" pursued by Su Bingqi, that is the foundation. "Science reflects the objective world based on logical thinking, and art reflects of the objective world based on image thinking while feel is definitely not replaceable for the image of sight in the effect of image thinking. "Daiyu taught Xiangling poetry, Kang Youwei guided middle-aged Liang Qichao in calligraphy [7], their teaching both involved the pre-culture of feel of art. For example, Daiyu listed a beautiful and serious literature of books, for teaching Xiangling reading poetry and assessing poetry, to advance XiangLing accumulate poetic connotations before create poems, while Liang Qichao can make effective interaction with Kang Youwei in calligraphy teaching only because he had the calligraphy foundation of long-term practice for imitating Yan Liu's copybook and studying inscription rubbings, which made him get a flexible transition of calligraphy style. Their art teaching is closely related with the language and words that are used by them all times, so there is little barrier between them in understanding each other.

However the indispensable "feel" for architecture has highly vocational personality, and the poetic blueprint of Beijing City Wall Park "Fig. 3" with a total length of 39.75 kilometers always stays in the drawing paper, just because its decision-makers have no enough professional "feel" of architecture. Even in ingenious use of "feel", we may be entangled with the interest how to build thousands of mansions with building materials imperturbably and in ecstasies. "Interest" is our best teacher to learn unfamiliar disciplines. If we have no the interest to find questions, study and solve problems, "practice by self after guided by the teacher" will become bragging.

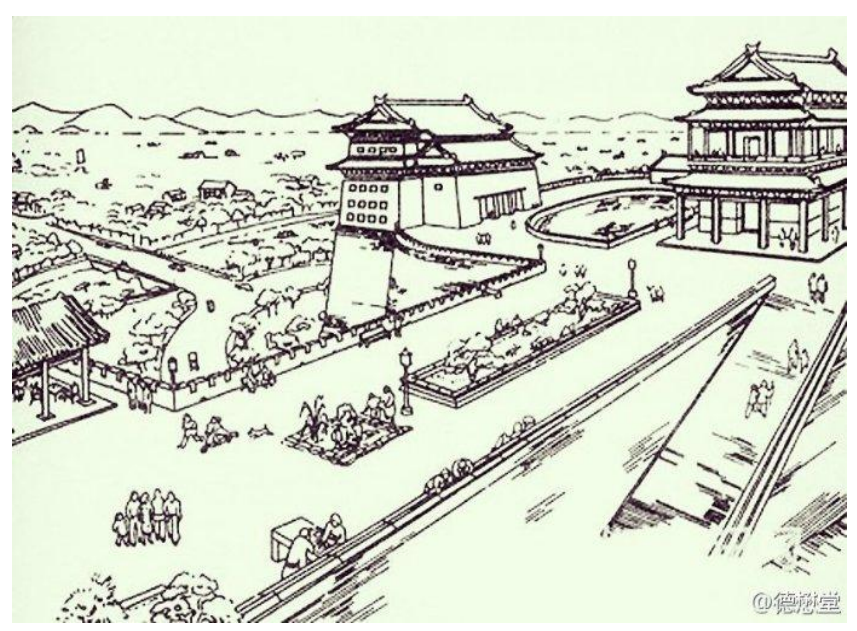

Fig. 3. The sketch of Beijing City Wall Park imagined and planned by Liang Sicheng in 1951

"Consolidating foundation" and carrying out different teaching framework for the students in the same class. Referring to the two-way educational philosophy of "conventional classes and experimental classes", we should follow the conventional framework of education for the students who are qualified for professional "feel", but for the students in lack of professional "feel", we should consolidate their foundation knowledge and make them absorb the advantage of Beaux-Arts system in basic education of architecture, help them lay solid foundation, understand and love the strange generalized humanities, great art and other design areas, in order to cultivate their "feel" and interest, improve their professional foundation to avoid its adverse effects in subsequent design training, and require them to accumulate general knowledge or skills necessary for profession change.

B. Like Two Flowers in Different Branches, They would Be Picked up One after Another ---. Gradually Strengthen the Design Training of "Developing Fully" and Carrying out Different Teaching Framework for the Students of the Same Course.

Zeng Guofan had a learning story of "stupider than the thief": One night, he was studying an article at home, and 
still midnight he could not deliver a recitation, which made vexed the thief hiding on the roof, so the thief jumped down and said to him: "You're so stupid, why do you have to read book? But I have recited the contents just after heard it several times"! So the thief recited the article from end to end, and then swaggered off. The "clodpate" Zeng Guofan stuck to practice in article and calligraphy all the time, and finally got comprehension and creativity. The literary quotation of "Ink Pond" and "Brush Pen Tower" also reflect the important role of perseverance for apprenticeships. Daiyu teaching poetry and Kang Youwei explaining calligraphy both highlight the leading role of teachers in arts education. In the Japanese teleplay of "Woman Dab of Volleyball", the father tied a ball in the high air, asked his daughter Oka Junko who were still in her childhood to jump up for reaching the ball year after year, by which he trained her superior jumping ability. Later, Junko joined the women's volleyball team of a high in Tokyo and she hardly studied and practiced every day and finally successfully created two powerful spiking ways of "Bolt from the Blue" and "Phantom Tornado". Her clear objective is to see her mother far apart from each other but she thought that can be achieved only playing the volleyball, so her objective has attracted and inspired Junko, to prompt her enthusiasm to dive into a long and tough volleyball training. In previous practice training, many different and disoriented instructions made students did not what to do, so students feared of study and played truant. We should bind students to "graduation" openly to drive students to be diligent in thinking and practice.

The theory of $\mathrm{M}$ in 1990s pointed out: an ant is walking around on a piece of paper and height has no meaning for it, that is to say, the third dimensional space is there, but is not have recognized by the ant. Similarly, we have the higher dimension - four-dimensional world (three spatial dimensions, one time dimension), so we are able to insight into the two-dimensional world of ants. The theory of $\mathrm{M}$ can be used to explain the progressive process of students at different ability levels. The development of ability is slower than the acquisition of knowledge, and sometimes it has recession. People usually have general ability, with wide range of use, meeting the requirements of many activities including the college entrance examination; and special ability is also known as specialized ability, mainly working in particular areas of activity. Long-term reasonable training can improve the formation of ability. [8] According to the circular creative skills interface chart "Fig. 4", it is analyzed that some students of architecture evade graduation design of strict norms, just because they had evaded "GREAT" design training for many times by playing petty trick, resulting in a lack of special ability required for independent completion of graduation design.

After consolidating foundation and strengthening elementary education, develop fully and enrich design training, that is "Like two flowers in different branches, they would be picked up one after another". We should preserve the previous graduation design (short design A) and on this base, we add a graduation assumption task (long-term design B) that is suitable for lower grade and is blended with the Bauhaus's workshop construction training mode, and issue the graduation thesis defenses outline expressly, directly linked with the "long-term design B", and give out the stage training objectives, with difficult and easy requirements supplementing eachother, to make students take the initiative to learn. Learning step by step and achieving mastery through a comprehensive study of the subject are the sub-item design skills of different training modules. It is often not smooth to form special abilities for the fresh in architecture, they may be obsessed in a training link, which should be concerned by professional teachers to avoid teaching losses.

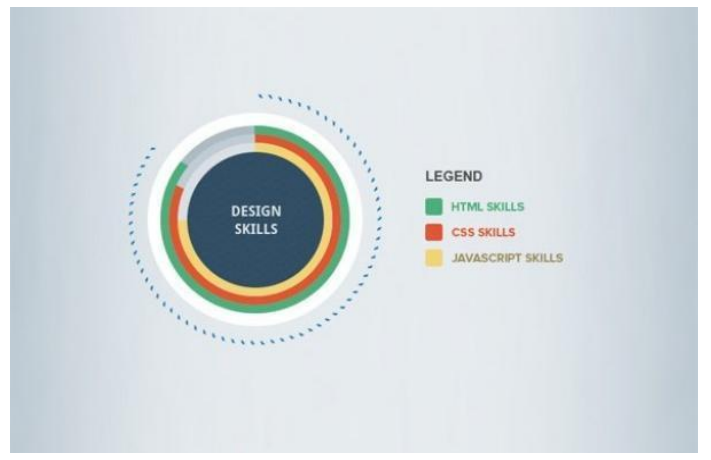

Fig. 4. Circular creative skills interface chart

C. Nature and Human Coexisting Peacefully, Rubbing up Clay for a Vessel by Keeping the Hollow Place in the Center--- with Mud Billet as Vessel Device - "Optimizing Results ", Mastering Flexible System of Social Education

Watch the decline as well as the prosperity. Start from the period of the Hundred Day's Reform, people from above to below give up the selection of scholars of old system with rules and regulations to save the country; while in today's China that practical creation has become the core of education, continuous argument about justice and benefit has damage the heavy pursuit of a group of people who pursue culture-ceducation formulary, the imperial court educates the common people at their own will like shaping the clay into pottery.

Scholastic year system and the credit system originate from the Soviet Union school system and western school system respectively. And the latter is limited by the reality of many colleges and universities and not hypercorrect for the original scholastic year system. The period of schooling of undergraduate course is difficult to reach a consensus: for example, Chien Wei-zang proposes four years while Liang Sicheng sets six years of schooling only for architecture major. Students with early initiating intelligence spend fours years in completing all credits while students with late initiating intelligence won't complete in spending six years, or some worldly-wise students is temporary absence from school to adjust. The objective fact is that the minds of students in the undergraduate courses of architecture is not unified and their force and skill is not uneven, for example, schoolgirls only have 55 percent of physical power and 65 percent endurance of schoolboys. There aren't too many Schoolgirls who can flexibly adapt the direction of elite 
education or vocational education of design specialty only depending on the intelligence of themselves. The "thick line assembly line" reflecting the general character of regular course education also ignores the "joint design" of architecture graduates falling from art tower of ivory to all living things: students of architecture who get used to ideal and romance often ignore the practical significance of undergraduate degree. There is no lack of such people who pretend to be Chu-Ko Liang, a person of great wisdom and resourcefulness "cry for the death of Zhou Yu". Besides, "A class B horse [10]", fiddling with the right and wrong maybe can cause the environmental effect of "persistent rumors against someone can shake the strongest confidence in him [11]". The cultivation of diabolism is eternal sad, won't die and is difficult to become a useful person [16], just like Qianmu said, "men in the street only pay attention to things on the table, such as how about the chancellor and how about six ministries; they don't pay attention to things under the table have strength and influence as well, ... things flowing on the table are called clear stream, and things flowing under the table are called turbid flow, ... All the things falling into the hand of petty official, the selection of official can be fast or slow, the punishment can be heavy or light, finances and taxes can be abused or changed, ceremonies can be held or abolished, human life can be threw or kept, the litigation prison can be big or small, and the project can be increased or decreased,...The background of number one scholar, the second place at palace examinations and number three in national civil examinations in feudal China also become a kind of sense of hierarchy" [12].

"We must understand the principle of China or the world; and we must have a good knowledge of the principle in the ancient and the modern" [10]. There is a saying: "Peach spends three years bearing fruits, apricot four years and plum five years, walnuts six years and persimmon seven years. The wild jujube can be sold for money after one year. If you want to eat ginkgo, you must wait for several decades". Du Shaoqing in The Scholars "doesn't take the provincial examination and imperial competitive examination and the annual assessment, free and easy" is the self depiction of $\mathrm{Wu}$ Jingzi, the great writer in Qing dynasty. [13] The scholar Zhang Xuecheng in Qianlong and Jiaqing period once read very slowly and his body is sick and weak, "only read one hundred words or so in one day, and then he is sick again and stops to read". After 20 years old, he school work makes great progress, but he becomes a successful candidate in the highest imperial examinations until he is 41 years old. Su Manshu becomes a monk at the age of 16. Later he resumes secular life constantly, falling in love and becoming ranger. The time when trees harvest the fruits is different, and talents "understand the principles early or later [14]", the early or late of mature cannot lump together and we cannot lose its "avidya" and force all the graduates "bearing fruits" and obtain evidence at the same time.

When getting rid of the old tsarist Russia school system and getting into a difficult position and being isolated, the bookish "Renaissance style figure" Lomonosov has dull words and only one word is left- "Without reading, I would rather die". The education collective absolutely can punish him to do a lifetime of hard labor, but finally they help him to avoid the misfortune of squeezing out and guide deviant son of the fisherman to the vision of "no child is left behind and the education is fair". "The rise of person of exceptional ability must rely on something" [10], "optimize the fruits"conform to the requirements of choosing and employing persons of the talent market and tailor make the "detachable, upgrades available, not concealing the evil and no false beauty" "package of leaving school". It is the flexible social education system which can achieve master through a comprehensive study, promotes the advantages helpful for learning of the credit system of "flexibility, agility, compatibility and being popular in schools", not only stresses easy to get in but hard to get out, but also adjust period of schooling, the direction of assessment and the stiffness control in the aspect of degree distribution. Only in this way can we help architecture graduates of uneven talent and quality to steadily connect the talent market, "use all direction extending education to establish an all direction extending society" [16].

\section{REFERENCES}

[1] Dream of the Red Chamber, Article 48. "Xue Pan, the pornographic overflowing people, suffers drubbing because he molests Liu Xianglian. He wants to go out to play. Xiangling, the wife of Xuepan, admires the poetic talent of the girls, so she consults Daiyu and works hard to recite poems"

[2] Qu Yuan, Ode to the Orange

[3] Vitruvius, The Ten Books on Architecture

[4] An Outstanding Artist is a Mental Patient with Artistic Talent

[5] Analysis on the Current Situation of Chinese Modern Art Design

[6] Analects

[7] Zhang Tiehua, Study and Comparison of the Influence of Kang Youwei's Calligraphy Concept on Liang Qichao, Chinese Library Classification Number J209, Article Identification Code A, Article Serial Number 1008-9675 (2014) 06-0066-06

[8] Ye Yiqian, Zhu Beili chief editor, Psychology, East China Normal University Press, edition 2010, ISBN978-7-5617-1338-9/B·077

[9] Pan Yue, Ode to Western Expedition

[10] Song Yanshen chief editor, Outline of History of Chinese Historiography, Northeast Normal University Press, edition 2012, ISBN978-7-5602-0893-0/k 68

[11] Chen Shou, The History of the Three Kingdoms, the Biography of the Monarch in $\mathrm{Wu}$

[12] Qian Mu, The Gain and Loss of the politics in Ancient China

[13] Wu Jingzi, Leisurely Sit in the Humble Cottage and Comment on The Schoolars

[14] Han Yu, The Teacher Said

[15] Arranged by Ye Jiaying, Gu Zhijing, Poetry Record of Gusui, China Renmin University Press, edition 2010, ISBN978-7-3001-2020-1

[16] Tao Xingzhi's Theory on the Universal Education, Sichuan Education Press, edition 2010, ISBN978-7- 5408-5314-3 